lead to mandatory refusal of the application in accordance with the Road Traffic Act.

(8) Following the reinstatement of a licence the patient's clinician should be mindful to monitor the patient's mental health and compliance with any pertinent treatment. Medical practitioners must, in accordance with these guidelines, inform DV1A where they know that the patient is not complying with the treatment or their mental state has deteriorated to the point that they are likely to be a source of danger to the public. The General Medical Council ethical code allows such notification where the public are at risk and a patient has failed to fulfil the Road Traffic Act obligation to immediately inform DVLA. It is acknowledged that monitoring patient compliance can sometimes be impracticable.

(9) It is impossible to frame regulations for drivers with personality disorder (although matters may appear clear cut with psychopathic disorder), but it is likely that those constituting a danger can be identified by a record of police offences, not necessarily connected with driving (such as assault or drunkenness). These can be excluded on a non-medical basis, and can be dealt with/without any medical information.

A system of conditional licensing might be evolved.

The Royal College of Psychiatrists is aware that with the development of new treatments and changes in medical practice, these recommendations will need to be reviewed at regular intervals.

\section{Footnotes}

(i) Legislation states that severe mental handicap is an absolute bar by law, but learning disability is assessed by function.

(ii) Epilepsy has been excluded, since it is covered by existing regulations.

Approved by Council June 1993

\title{
College elections
}

\section{Candidates for election to Council}

Dr M. Alexander

Dr K. G. M. Bhakta

Dr J. Birley

Dr J. Holmes

Professor C. Katona

Dr P. Maddocks

Dr R. Williams

* Successful candidates.

\section{Candidates for election to the}

Votes Court of Electors

Votes

675 Professor F. Creed 1023*

698 Dr K. Day 713*

1469* Dr P. Fenwick 816*

1131* Professor H. Ghodse 769*

1104* Professor J. Gunn 1088*

768* Dr M. Lipsedge 846*

1022* Dr. K. Murray 536

Dr J. Robertson $\quad 503$

Dr C. Smith 609

Dr R. Symonds $\quad 467$

Dr G. Wallen 461

\section{College Manpower Census}

The first College Manpower Census has recently been completed. It is published as an occasional paper of Council (OP20) and is available from the Publications Department at a cost of $£ 5.00$. 